\title{
Cold drink cans contaminated with rat urine can kill
}

\author{
Jaspreet Kaur · Rup Lal
}

Received: 31 July 2009 / Accepted: 3 August 2009

(C) Association of Microbiologists of India 2009

Whether it is a hot day, a party or any celebration - the first thing a person does is to drink a can of 'soft' drink. Having a soft drink (especially cola) is considered by today's youth as something "cool". It might seem refreshing, it might taste good until one comes to know that the can's top was crusted with rat urine: Now, that's really "hard" on your health! Yes, the dried rat urine can lead to a bacterial zoonotic disease called leptospirosis, commonly known as Weil's syndrome. It is caused by pathogenic spirochetes of genera Leptospira that traditionally consist of two species L. interrogans and L. biflexa. It has emerged as a globally important infectious disease which causes enlargement of spleen, hepatic and renal failure or massive pulmonary hemorrhage [1]. The acute nature of this disease became evident from a recent incident reporting the death of a woman in Belgium after using such cans and was spread on internet as a cautionary tale (www.urbanlegends.about.com). The investigation revealed that the top of the can was contaminated with dried rat's urine which is toxic and lethal. Some people dismissed the episode as a misconstrued report, intended to spread sensationalism. Moreover, there is theoretical risk of human infection from residual rat urine (only if the rats are infected) on cans or bottles but the statistical risk is extremely small [2]. But even then, the news contains an important information which is noteworthy because the dreadful truth is that even the most modern, superstores have rodents and the cans or bottles may have been stored or handled in an unsanitary manner before they get transported to the retail outlets without being properly cleaned. It is well known that the rodents are reservoirs of parasites and they eat and contaminate as much food as they

J. Kaur · R. Lal $(\bowtie)$

Molecular Biology Laboratory,

Department of Zoology, University of Delhi,

Delhi - 110 007, India

E-mail: ruplal@gmail.com eat with urine, droppings and hair. They also carry different kind of diseases including bubonic plague, murine typhus, spirochetal jaundice, rabies, rat bite fever and bacterial food poisoning but hantavirus pulomonary syndrome (HPS) and leptospirosis are two fatal diseases that have been constantly in the news recently. HPS is a respiratory disease, caused by Sin Nombre virus which is a type of hantavirus. It thrives in dried droppings of rat which can be easily inhaled and ingested like dust. Most hantaviruses attack kidneys, but the Sin Nombre virus attacks lungs. It infects the walls of lung capillaries, making them leak and flooding the lungs with fluid. The spectrum of human leptospirosis is extremely wide ranging from milder form (Anicteric leptospirosis) to severe syndrome of multiorgan infection with high mortality (Icteric leptospirosis) [3]. Both HPS and leptospirosis are treatable if properly diagnosed. Prevention is largely dependent on sanitation measures and using hygienic methods such as avoiding direct and indirect human contact with animal urine. The main preventive measure for these diseases is to create awareness about them by an intensive educational campaign. But, despite known disadvantages, there has been a rise in soft drink consumption, especially in younger generation, due to the various attractive advertisements shown by soft drink manufacturers to lure people.

Finally, as the timeless adage goes: "It is better to be safe than sorry", it becomes imperative to wash all the canned beverages before consuming them just as you wash your vegetables and fruits.

\section{References}

1. Bharti AR, Nally JE, Ricaldi JN, Matthias MA, Diaz MM, Lovett MA, Levett PN, Gilman RH, Willig MR, Gotuzzo E and Vinetz JM (2003) The Lancet Infectious Diseases 3:757-771

2. www.leptospirosis.org

3. Levett PN (2001) Leptospirosis. Clinical Microbiology Reviews 14:296-326 